\title{
Assisted Migration and Latitudinal Limitations of Whitebark Pine
}

\author{
Jesse Wood * \\ The University of Victoria \\ jessewood123@hotmail.com
}

\begin{abstract}
Whitebark pine, a high alpine tree species, is limited up to $55^{\circ} \mathrm{N}$ despite uncolonized suitable habitat that exists in Northern British Columbia. It is unclear what limits its northward distribution. Whitebark pine is dependent upon a bird species, Clark's nutcracker, for its seed dispersal, therefore, the bird's limitations must be examined. As optimal seed caching sites are located in recently burned sites, this paper hypothesizes that the fire regime in northern forests is not conducive for the creation of these sites. Assisted migration projects must focus more attention to long-term regeneration by addressing the needs of Clark's nutcracker.
\end{abstract}

Keywords:Whitebark pine; Pinus albicaulis; Clark's nutcracker; Nucifraga columbiana; assisted migration; species range limits; restoration; conservation

\section{INTRODUCTION}

W hitebark pine (Pinus albicaulis) is an endangered tree species located in the highest forested sites in the northwestern United States and southwestern Canada (Tomback, Arno, \& Keane, 2001). Whitebark pine plays a critical role in the high alpine ecosystems, producing food, shelter, and influencing watershed hydrology (Tomback et al., 2001). The distribution of whitebark pine is shrinking due to white pine blister rust (Cronartium ribicola; further referred to as WPBR), mountain pine beetle (Dendroctonus ponderosae; further referred to as MPB), fire suppression (which leads to enhanced competition from other tree species), and climate change (Tomback et al. 2001). Climate change is forcing the migration of whitebark pine to higher elevations and higher latitudes, but the slow reproductive rate of whitebark pine may inhibit the drastic migration needed to sustain the species (McLane \& Aitken, 2012). Bower and Aitken suggest that the only hope for this species' survival is restoration of the whitebark pine habitat by means of migrating blister rust resistant genotypes "along environmental gradients and into areas of new potential habitat" (p. 74). This process of transplanting seedlings to uncolonized areas will be referred to throughout this paper as assisted migration. Species distribution models (SDMs; which show the predicted range of a given species) show that, although much of whitebark pine's current range will be lost due to climate change, a similar sized suitable climate will emerge in northern British Columbia (BC); (McLane \& Aitken. 2012). Interestingly, these models also reveal that whitebark pine does not inhabit all of its current suitable climate range in northern BC (Hamann \& Wang, 2006). As whitebark pine is dependent upon Clark's nutcracker (Nucifraga columbiana) to disperse its seeds, this paper hypothesizes that the latitudinal limitations of whitebark pine are rather limitations of Clark's nutcracker (Tomback, 1982). It is then hypothesized that a possible explanation for the latitudinal limits may be related to the

${ }^{*}$ I would like to thank Jill Harvey for her encouragement, insight, support, and contagious passion for trees. I would also like to thank my family, Allie Simpson and Laurie Waye from the Arbutus Review for their continued support. Finally, I would like to thank the anonymous peer reviewers for their helpful recommendations and questions. 
fire regime of northern forests, which may not be conducive for Clark's nutcracker, as it has an affinity to cache its seeds in recently burned sites (Tomback, 2001). For this reason, the ecological interactions between these two species should be further understood and be given higher priority in restoration research. Future research in this area could improve the success of assisted migration restoration projects and will be explained in greater detail in this paper. This paper will be of most interest to those working in government, forestry, and various academic disciplines such as geography and biology. It is my hope that this paper will serve to draw attention to an endangered species and generate discussions that may build upon the ideas shared in this paper. Coupled with further research, assisted migration, if conducted properly, may prove to be an effective means to protect an endangered species (and ecosystem) that will likely disappear without active human intervention.

\section{Whitebark Pine Ecology and Significance}

Whitebark pine inhabits windy, moist climatic zones which experience short, cool summers and long, cold winters (Arno \& Hoff, 1989). Whitebark pine stands may be pure or mixed with lodgepole pine in areas with low precipitation, Engelmann spruce and subalpine fir (ESSF) in the Rockies, and mountain hemlock in the Coastal Mountains and the Cascades in BC (Arno \& Hoff, 1989). Whitebark pine's large seeds are an important food source for a variety of species including Clark's nutcracker, squirrels, and grizzly bears (Tomback \& Kendall, 2001). Whitebark pine is a keystone species, a species whose impact on its environment is disproportionately large given its abundance (Tomback et al. 2001; Paine, 1995). It protects watersheds through regulating runoff and reducing soil erosion as it stabilizes the soils in the high alpine regions in which it grows (Tomback et al. 2001). Whitebark pine promotes biodiversity and facilitates succession (the development of the ecological community over time) by creating microclimates more conducive for the colonization of other species (Tomback et al. 2001). Whitebark pine is also known for providing food and various types of shelter for a host of vertebrate and invertebrate species. For these reasons, the loss of whitebark pine would alter watershed hydrology, successional processes and the diversity of high alpine communities (Tomback et al. 2001).

Interestingly, the existence of whitebark pine is dependent upon a single species of bird to disperse its seeds. Whitebark pine has a mutualistic relationship and hypothesized coevolution with Clark's nutcracker (Tomback. 1982). Whitebark pine seeds are very large, wingless, high in fat, and are the primary food source of Clark's nutcracker (Tomback, 1982). This bird is responsible for the dispersal and reproduction of whitebark pine as it creates seed caches of three to seven seeds, two centimetres below the soil surface, in sites ideal for seed germination (Tomback, 1982). Although other species such as mice, squirrels, and chipmunks collect and store seeds, cache and site conditions chosen by these animals are less conducive for germination and are less abundant (Tomback, 1982). With little effective dispersal from other animals, the establishment of whitebark pine seedlings is, therefore, almost completely dictated by Clark's nutcracker. Thus, Clark's nutcracker habitat and behaviour is of utmost importance to the preservation of whitebark pine. The following paragraphs will elaborate on the role of climate change on whitebark pine, its geographic distribution, its habitats requirements, current restoration initiatives, and the requirements for assisted migration. Drawing information from these topics, I conclude with recommendations for future research and restoration. 


\section{BiogeOgRAPHY}

\section{Climate Change}

Along with WPBR, MPB, and fire suppression, climate change poses a significant threat to whitebark pine (Kendall \& Keane, 2001). Arno notes that whitebark pine is a slow-growing species, taking around 65 years to produce female cones (Kendall \& Keane, 2001). McLane and Aitken (2012) suggest that with the current rate of climate change and the slow reproductive rate of whitebark pine, the species will not be able to adapt or migrate at a fast enough rate to save it from extinction. Hamann and Wang's SDM generated for BC's biogeoclimatic zones show that by $2025,59 \%$ of the current whitebark pine habitat will be lost while $52 \%$ new habitat will be created (2006). By 2085, the percentages will increase to $73 \%$ and $76 \%$ respectively (Hamann \& Wang, 2006). Interestingly, it was also noted in Hamann and Wang's models that whitebark pine was observed in only $54 \%$ of its current predicted range (2006). Whitebark pine ceases to exist beyond $55^{\circ} \mathrm{N}$ in BC. In another SDM created by Wang for McLane and Aitken (2012), the majority of the uncolonized suitable area lies in northwestern BC. By planting whitebark pine seeds in various locations within the predicted areas north of its current observed range, McLane and Aitken (2012) have proven that whitebark pine is able to establish. Their findings support their SDMs and eliminate climatic conditions as the sole limiting factors for the species' northward colonization. The development of restoration programs must then consider both the changing climatic conditions as well as the existing limitations restricting the species.

\section{Latitudinal Limitations}

It remains unknown why whitebark pine does not currently grow at latitudes beyond $55^{\circ} \mathrm{N}$ in BC despite the suitable climate that exists (D. F. Tomback, personal communication, November 23, 2014; McLane \& Aitken, 2012). McLane and Aitken (2012) determined that snow pack and snowmelt timing may affect the germination of whitebark pine, but it is unlikely that those factors alone restrict whitebark pine's northward colonization. A combination of climatic and nonclimatic factors likely dictate the species range. I hypothesize that the latitudinal limitations of whitebark pine are actually limitations of Clark's nutcracker. It is possible that the uncolonized habitat in Wang's models may be suitable for whitebark pine, but not for Clark's nutcracker. The presence of Clark's nutcracker "seems somewhat unpredictable at the northern end," and "there are fewer alternative seed sources to support them" (D. F. Tomback, personal communication, November 23, 2014 and May 24, 2015). While limited alternative seed sources could be contributing to the latitudinal limits, I hypothesize that there are multiple factors influencing the range limits of Clark's nutcracker: most notably, the availability of optimal seed caching grounds. Such optimal caching grounds can be created through disturbance; thus, fire plays an important role in maintaining the structure of the high alpine community (Tomback. 2001).

\section{Importance of Fire}

Whitebark pine is a pioneer species that is often the first conifer species to establish after a stand-replacing event (a disturbance that has killed most or all of the trees in the stand) (Tomback et al. . 2001). The hardiness of its seeds, its shade intolerance, and its effective dispersal method (Clark's nutcracker) enable it to establish quicker and in greater abundance than wind-dispersed species in recently disturbed areas (Tomback, 2001). It also is less flammable than its subalpine competitors, increasing its chance of survival in the event of ground fires (Tomback et al., 2001). These adaptations allow whitebark pine to thrive in environments with mixed-severity fires. 
Whitebark pine is able to establish quicker than its competitors as Clark's nutcracker cache their seeds in open, disturbed sites, and have an affinity for recently burned sites (Tomback, 2001). I hypothesize that northern $\mathrm{BC}$ does not have a fire regime suitable for the creation of nutcracker caching sites. Similar to the effects of fire exclusion, successional replacement (replacement of whitebark pine by Englemann spruce and subalpine fir) would also occur in areas with long fire return intervals. Arno (2001) notes that whitebark pine fire intervals typically range from 50 to $300+$ years and fires are typically of mixed-severity. I hypothesize that southern BC experiences more frequent, less severe fires than northern forests in the same biogeoclimatic classification. At latitudes higher than $55^{\circ} \mathrm{N}$, the ESSF zone could have a fire regime that is less optimal for whitebark pine and Clark's nutcracker caching grounds. Restoration programs should, therefore, consider further research on the latitudinal differences in fire regimes in high alpine communities along with identifying other potential limitations for Clark's nutcracker.

\section{Restoration}

\section{Current Restoration Initiatives}

Academic literature, research, and governmental restoration initiatives, in both Canada and the United States, indicate that whitebark pine is a species that many people are passionate about saving, as it is essential to ecological health on a local and regional scale. As whitebark pine seeds can be an important dietary component for grizzly bears, an iconic species in the northwest, they receive more public interest than they might otherwise. In 2012, whitebark pine was listed as an endangered species under the Species at Risk Act (SARA), giving it legal protection in Canada (Species at Risk Public Registry, n.d.). The provincial governments of BC and Alberta recognize the tree's ecological value and have both established restoration programs (BC Parks, 2012: Alberta Whitebark Limber Pine Recovery Team, 2014). Silvicultural restoration techniques alter the forest structure, through selective tree cutting, for various desired outcomes. Practitioners may remove individual trees infected with WPBR or MPB, remove competing tree species (such as Engelmann spruce and subalpine fir), create openings for caching sites for Clark's nutcracker, and create fuel (by leaving cut trees) for future prescribed fires (Tomback et al., 2001). Other common restoration techniques that are often used in tandem with structure alteration are prescribed burning and the planting of rust-resistant seedlings (Tomback et al., 2001). In 2011, the BC Ministry of Forests, Lands and Natural Resources (2014) began a restoration program that involved the collection of seeds from rust-resistant genotypes in the Selkirk Mountains. Planting occurred in the summer of 2014 on three sites: Nelson (1000 seedlings), Revelstoke (1000 seedlings) and Cranbrook/Kimberley (2000 seedlings) (Ministry of Forests, Lands and Natural Resource Operations., 2014, October 20). Additionally, Parks Canada has implemented prescribed burns on Mt. Greenock in Jasper National Park in attempts to create more whitebark pine habitat as historical fire exclusion policies in northwestern US and southern BC have led to successional replacement of whitebark pine by subalpine fir and Engelmann spruce (Species at Risk Public, n.d; Tomback et al., 2001). Research and restoration efforts in Manning Park have resulted in the planting of seedlings in 2011 as part of BC Parks 100 year celebration (BC Parks. 2012). While these restoration efforts address the threats from the WPBR, fire suppression, and MPB, they may be futile if the restoration sites are to become inhospitable in the coming decades. More drastic restoration initiatives must be utilized based upon our knowledge of whitebark pine's reproductive rate, the predictions of shifting habitat due to climate change, and the unknown factors currently limiting its range expansion. 


\section{Assisted Migration: An Emerging Restoration Technique}

Due to its unique high alpine range, slow reproductive maturation, and its poor competitive ability, whitebark pine is unlikely to become an invasive species if transplanted in an assisted migration project (McCaughey \& Tomback, 2001: McLane \& Aitken, 2012). As very few species, especially conifers, can endure the harsh high alpine conditions at which whitebark pine grows, it poses little threat to the native vegetation; rather, it creates microclimates more conducive for the colonization of other species (Tomback et al., 2001).

Rather than create temporal guidelines based upon the species reproduction, Bower and Aitken (2008) suggest geographical and temperature guidelines for transporting seedlings: up to $1.9^{\circ} \mathrm{C}$ in mean annual temperature of the coldest month in the northern region and $1.0^{\circ} \mathrm{C}$ in the Rocky Mountain region. This translates to 505 kilometers northward in the northern region of the province and increased elevation of 320 meters in the Rocky Mountain region (Bower \& Aitken, 2008). These guidelines increase the likelihood of seedling establishment and decrease the potential for cold-related injuries. Along with the seed transport temperature guidelines given above, Bower and Aitken (2008) recommend avoiding the transfer of seeds between mountain ranges and caution against exceeding the temperature guidelines as doing so may lead to maladaptation (traits that become more harmful than helpful). Translocating seeds from multiple locations may have adverse effects on the local population, reducing local adaptation, productivity, and health (Aitken \& Whitlock, 2013). However, in the face of climate change, it could be beneficial to facilitate assisted migration of individuals to promote adaptation to the changing climate (Aitken \& Whitlock. 2013). Mahalovich et al. (2006) found that each seed zone they examined had enough genetic diversity (having rust resistant and cold hardy seedlings) to facilitate breeding and restoration programs. Due to the high mortality rates caused by the WPBR, rust-resistant and cold hardy genotypes need to be identified and collected for migration following the temperature guidelines established by Bower and Aitken (2008).

\section{Recommendations}

Current restoration efforts and proposed assisted migration programs have not prioritized further understanding of Clark's nutcracker habitat limitations and behaviour. The Alberta whitebark pine recovery plan does stress the importance of the Clark's nutcracker, although their perceived threat is that the numbers of Clark's nutcracker will diminish as seed density decreases due to the death of trees infected with WPBR and MPB (Alberta Whitebark Limber Pine Recovery Team, 2014). Of moderate priority on their list of research priorities is "current and future habitat for Clark's nutcracker" (Alberta, 2014, p. 28). Although this knowledge gap may be classified as a moderate priority in Alberta (as whitebark pine is found in all of Alberta's high alpine environment), in $\mathrm{BC}$ it should be classified as a high priority because there are unclear limiting factors for both whitebark pine and Clark's nutcracker.

The introduction of whitebark pine at higher latitudes has the potential to change patterns of predation in species which use whitebark pine seeds as a food source, such as grizzly bears, squirrels, and Clark's nutcracker. Before an assisted migration project is undertaken, its interactions with the regional wildlife should be understood and examined. This could be carried out by examining the results of previous restoration initiatives such as in Yellowstone National Park.

To ensure the long-term viability of human-planted whitebark pine populations, assisted migration project sites should be located in the ideal habitat for Clark's nutcracker. If no habitat currently exists, it could be established through various means such as creating small openings in the forest for caching sites (Tomback et al. 2001). To successfully facilitate assisted migration projects, prescribed fire techniques, replicating ideal cache-creating fire regimes should be used. 
Creating ideal nutcracker habitat north of its current range could facilitate the natural migration of Clark's nutcracker and potentially facilitate the natural colonization of whitebark pine along environmental gradients. Establishment of whitebark pine stands through assisted migration could naturally attract Clark's nutcracker, especially as the climate continues to warm. If the natural migration of Clark's nutcracker does not occur, breeding pairs could be relocated after whitebark pine has established and is producing seed. Although the natural migration or introduction of Clark's nutcrackers would not occur until the trees began to produce sufficient seed, nutcracker habitat should be one of the main considerations with site selection in assisted migration and restoration projects.

\section{Conclusion}

The literature and my personal communications suggest that the latitudinal limitations of both whitebark pine and Clark's nutcracker are not well understood. Despite the unclear limitations, McLane and Aitken (2012) have proven that whitebark pine is able to establish north of its current observed range. Based upon their work, I have hypothesized that the latitudinal limitations of whitebark pine are rather limitations of Clark's nutcracker. Secondly, I hypothesize that Clark's nutcracker may be partially limited by available caching sites due to the differences in the fire regimes between southern and northern forests. To my knowledge, these hypotheses have not been explicitly stated in the academic literature. Although I have not undertaken field work (gathering data) to support my hypotheses, I hope that this publication serves to generate critical thinking by readers that may then contribute to this topic. To save an ecologically significant species and ecosystem, I argue that restoration initiatives should prioritize research on the limitations of Clark's nutcracker. An altered fire regime is one of the many explanations for the current lack of northern colonization, therefore more research on the limiting range factors of Clark's nutcracker should be undertaken to better understand both species' ranges. This research would greatly benefit the emerging restoration technique of assisted migration. Given the mutualistic relationship between Clark's nutcracker and whitebark pine, assisted migration projects must address the habitat requirements for Clark's nutcracker if the transplanted stand is ever to naturally regenerate (rather than rely on human planting). Assisted migration projects should consider using restoration techniques such as prescribed burning to create the ideal habitat for both whitebark pine and Clark's nutcracker. In order to maintain viable whitebark pine populations, assisted migration projects must: 1) be located within Clark's nutcracker's current range; 2) implement strategies to relocate breeding pairs once the stand produces seed; or 3) encourage natural migration to established whitebark pine stands. Assisted migration projects, in facilitation with research on fire regime and Clark's nutcracker range limitations, could be an effective means to save whitebark pine from extinction and diversify high alpine environments.

\section{REFERENCES}

Aitken, S. N., \& Whitlock, M. C. (2013). Assisted gene flow to facilitate local adaptation to climate change. Annual Review of Ecology, Evolution, and Systematics, 44, 367-388.

http://dx.doi.org/10.1146/annurev-ecolsys-110512-135747

Alberta Whitebark Limber Pine Recovery Team. (2014). Alberta Environment and Sustainable Resource Development 2013-2018. Alberta Environment and Sustainable Resource Development, Alberta Species at Risk Recovery Plan No. 34. Edmonton, AB. 
Arno, S. F. (2001). Community types and natural disturbance processes. In D. F. Tomback, S. F. Arno, \& R. E. Keane (Eds.), Whitebark pine communities: Ecology and restoration. Washington, DC: Island Press.

Arno, S. F., \& Hoff, R. J. (1989). Silvics of whitebark pine (Pinus albicaulis), General Technical Report. INT-GTR-253. U.S. Department of Agriculture Forest Service Intermountain Research Station. Research Station, Ogden, Utah, USA.

BC Parks. (2012). BC Parks 2011/2012 Annual Report. Retrieved from http://www.env.gov.bc.ca/ bcparks/bc-parks-annual-report-dec12.pdf

Bower, A. D., \& Aitken, S. N. (2008). Ecological genetics and seed transfer guidelines for Pinus albicaulis (pinaceae). American Journal of Botany, 95(1), 66-76. http://dx.doi.org/10.3732/ajb.95.1.66

Hamann, A., \& Wang, T. (2006). Potential effects of climate change on ecosystem and tree species distribution in British Columbia. Ecology, 87(11), 2773-2786. http://dx.doi.org/10.1890/0012-9658(2006)87\%5B2773:peocco\%5D2.0.co;2

Kendall, K. C., \& Keane, R. E. (2001). Whitebark pine decline: Infection, mortality, and population trends. In D. F. Tomback, S. F. Arno, \& R. E. Keane (Eds.), Whitebark pine communities: Ecology and restoration (pp. 221-242). Washington, DC: Island Press.

Mahalovich, M. F., Burr, K. E., \& Foushee, D. L. (2006). Whitebark pine germination, rust resistance, and cold hardiness among seed sources in the inland northwest: Planting strategies for restoration 2005. USDA forest service proceedings RMRS-P-43, Rocky Mountain Research Station, Fort Collins, Colorado, USA.

McCaughey, W. W., \& Tomback, D. F. (2001). The natural regeneration process. In D. F. Tomback, S. F. Arno, \& R. E. Keane (Eds.), Whitebark pine communities: Ecology and restoration. Washington, DC: Island Press.

McLane, S. C., \& Aitken, S. N. (2012). Whitebark pine (pinus albicaulis) assisted migration potential: Testing establishment north of the species range. Ecological Applications, 22(1), 142-153. http://dx.doi.org/10.1890/11-0329.1

Ministry of Forests, Lands and Natural Resource Operations. (2014, October 20). Whitebark pine experiment takes aim at blister rust. Retrieved from http://www.newsroom.gov.bc.ca/2014/10/ whitebark-pine-experiment-takes-aim-at-blister-rust.html

Paine, R. T. (1995). A conversation on refining the concept of keystone species. Conservation Biology, 9(4), 962-964. http://dx.doi.org/10.1046/j.1523-1739.1995.09040962.x

Species at Risk Public Registry. (n.d.). Species profile: Whitebeark pine. Retrieved from http:// www.registrelep.gc.ca/species/speciesDetails_e.cfm?sid=1086

Tomback, D. F. (1982). Dispersal of whitebark pine seeds by Clark's nutcracker: A mutualism hypothesis. The Journal of Animal Ecology, 51(2), 451-467. http://dx.doi.org/10.2307/3976

Tomback, D. F. (2001). Clark's nutcracker: Agent of regeneration. In D. F. Tomback, S. F. Arno, \& R. E. Keane (Eds.), Whitebark pine communities: Ecology and restoration. (pp. 89-104). Washington, DC: Island Press.

Tomback, D. F., Arno, S. F., \& Keane, R. E. (2001). The compelling case for management intervention. In D. F. Tomback, S. F. Arno, \& R. E. Keane (Eds.), Whitebark pine communities: Ecology and restoration (pp. 3-25). Washington, DC: Island Press. 
Tomback, D. F., \& Kendall, K. C. (2001). Biodiversity losses: The downward spiral. In D. Tomback, S. Arno, \& R. Keane. (Eds.), Whitebark pine communities: Ecology and restoration (pp. 243-262). Washington, DC: Washington, DC: Island Press. 